\title{
Creation of digital terrain models using software applications
}

\author{
Oksana Germak*, Oksana Gugueva, and Natalya Kalacheva \\ Don State Technical Universyty, 1, Gagarin square, Rostov-on-Don, 344010, Russia
}

\begin{abstract}
The article discusses the construction of a digital terrain model in various programs, which will be used for the vertical planning design. One of the major challenges in this area is the creation of an accurate and realistic surface, which will give an opportunity to create a quality and compliant site. To solve this problem and analyze, a model of the same territory and the same initial data has been built. The paper presents a construction algorithms DTM a method of constructing an irregular grid of heights, graphical implementation and analysis.
\end{abstract}

\section{Introduction}

Digital terrain model (DTM) can be created using photogrammetry (aerial photographs and satellite images), ground-based laser scanning, and ground-based geodetic measurements due to modern technological developments. The quality of the data collected to create DTM, and, above all, the quality of obtaining the points' height depends on the technology used. DTM is a numerical representation in which the topographic surface of all or part of the terrain is attempted to be represented as a mathematical surface with a certain number of points. The model consists of grid cells, each of which has a height value and is equidistant from each other [1]. In addition, this surface is attempted to be mathematically represented on a topographic surface based on control points, the three-dimensional coordinates of which are determined. The built elevation model realistic appearance depends on the number of control points and their proper distribution. So, the points of a sharp change in the relief (for example, the edge and the bottom of the slope), the points of the watershed line should be taken as reference points, considered separately or corrected later when building DTM. Digital terrain models built in this way will be more compatible with the actual topographic surfaces they represent.

Building a digital terrain model, based on the spatial interpolation method became possible due to the development and improvement of computer technologies, as well as software products.

There are various interpolation algorithms, which depend on the purpose and scope of the constructed model, on the way of digital representation.

In engineering and geodetic production, the most common ways to represent a digital terrain model are a regular grid of points' heights (matrix) on the terrain surface, an irregular grid (TIN model), vector lines.

* Corresponding author: oksanag2@yandex.ru 
Regular elevation grid: creates a grid of squares, rectangles or triangles, at the nodes of which the points with a known elevation are located. Interpolation (finding contours) is performed on each side of the grid. An important drawback in this method is the neglect of the significant relief points (points of a sharp bend in the relief - slope, points on watershed lines, etc.) when building a grid, which in turn affects the realism of the constructed surface.

Irregular grid (TIN model): a triangulation grid is generated from a group of points with known elevations, taking into account relief inflection lines and exclusion areas (for example, water surfaces, edges of construction sites).

Method of vector lines (contour lines or other isolines with equal or unequal step).

In the programs used by surveyors, the most commonly used interpolation method is interpolation based on Delaunay triangulation. This method consists in constructing triangles that do not overlap each other, at the vertices of which the control points are located; the length of the triangle edge is set; it is possible to adjust the degree of surface smoothness.

Purpose of the study: building DTM of a small area of undeveloped territory using various applications: Robur-Roads, AutoCAD Civil 3D, Credo Linear surveys, analysis of the constructed model, programs' analysis. The completed model will be used for the design of the relief vertical layout.

The object details: undeveloped territory, gentle relief.

Baseline data for the research: file of ground topographic survey data, unloaded from the electronic total station, in "txt format. The data included: the number of the picket, the numbers of the theodolite traverse survey stations, the coordinates and heights of all points and codes. The height of the relief section when building the model is $0.25 \mathrm{~m}$.

It should be noted that the study was carried out by a group of individuals who own all three programs. They built the models on the software of the same brand and with the same characteristics.

The familiar interface is the interface of the AutoCad program, so in the future it will be relied upon.

\section{Robur program}

Robur software product is a multifunctional system that supports the entire technological process - from survey to stakeout [5].

We note the convenience of working together with designers and one project over the network, as well as the ability to generate the necessary output documents (topographic plan, adjustment lists, a list of intersecting communications, a list of lines and curves, etc.) One of the main features of the program is the creation of a digital terrain model and work with surfaces. The digital terrain model is built by the method of generating an irregular grid of heights (TIN-model). To work with surfaces, Robur supports a wide range of functions: import and editing of the results of exploration and commissioning surveys, construction of structural lines and surfaces. Moreover, the surfaces can be built using the Robur functionality or imported from the survey processing packages.

\subsection{DTM plotting}

When plotting the model, we adhered to the following scheme:

1. Project creation

2. Surface import (data file)

After importing data in the tab "DTM- Eg (surface)" we get a cloud of points (Fig. 1) 


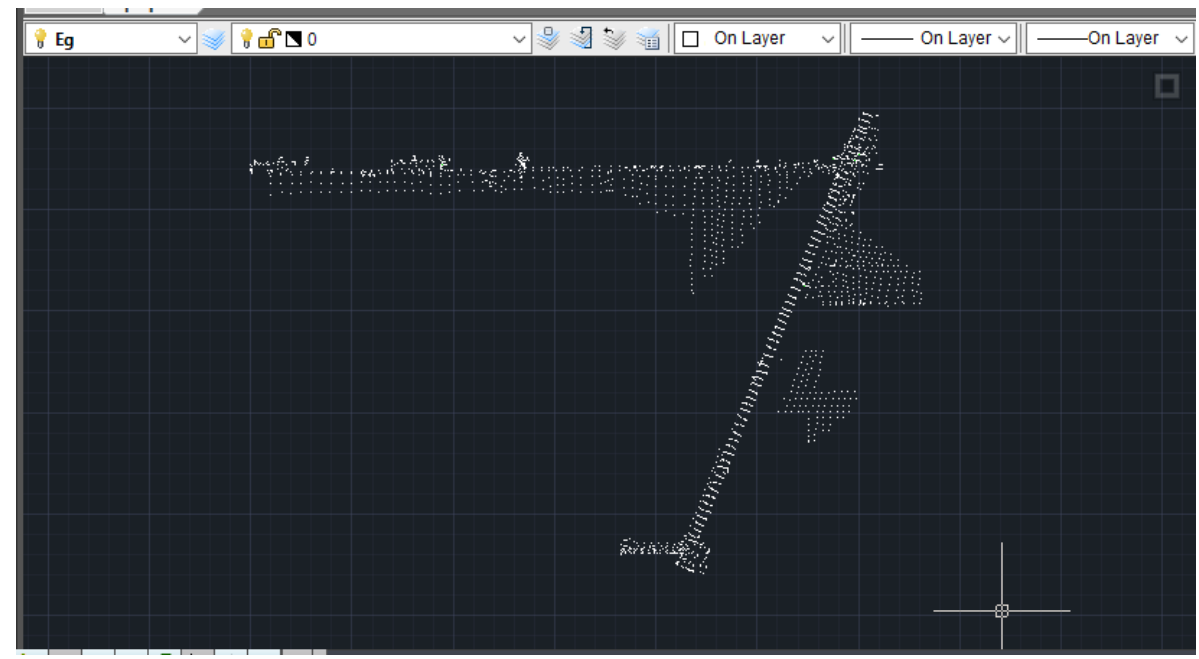

Fig. 1. Point cloud

3. Surface - Plotting - Replot the Surface

After the maximum length of the edge $(100 \mathrm{~m})$ has been set, the process of plotting the surface will start. As a result, the constructed surface was displayed in the working window of the program. Next, we evaluate the surface and, in the necessary places (duplicate points, characteristic bend points of the relief, slopes, etc.), we exclude high-altitude points from the grid, thereby moving the edges. The surface is replotted automatically. In the places where the distance between the adjacent points is greater than the maximum specified edge length, extra triangles, which did not reliably describe the terrain, were formed. These ribs were also removed.

4. Surface - Plotting - Flip the Edge.

5. Surface - Setting.

Contours are one way to visually analyze a surface. In the dialog box that opens, set the settings for the current DTM model: display of triangles, construction and display of contour lines, taking into account the section height, put down bergstrichs and labels of contour lines.

Received DTM with a grid of triangles is shown in Fig. 2.

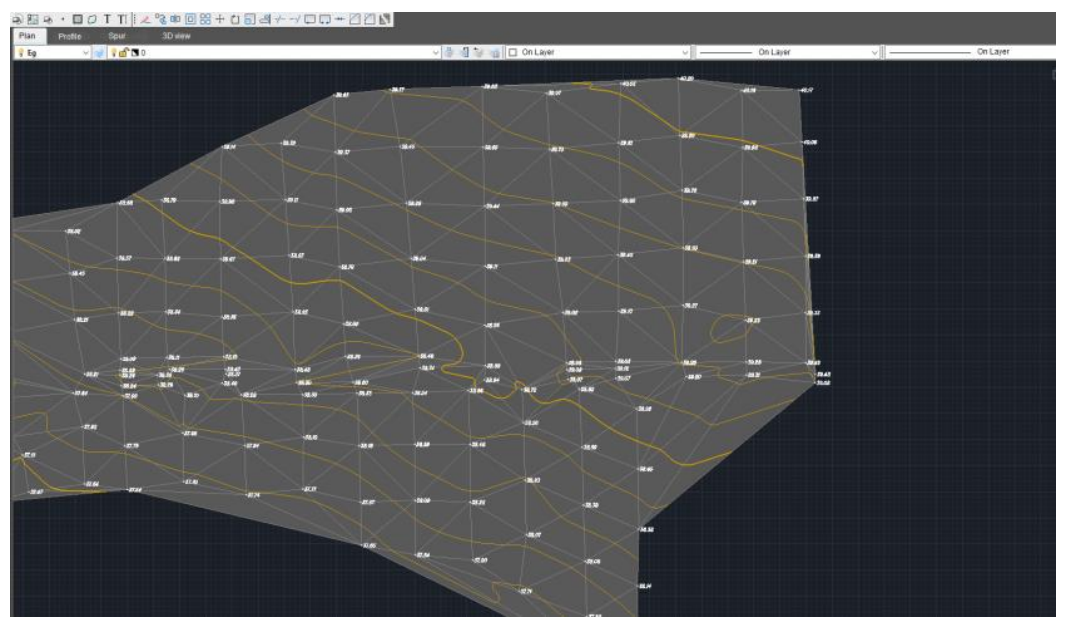

Fig. 2. DTM with triangulation grid 
Analysis of the constructed model: the model corresponds to the real topography of the area. Few of the edges of the triangles were subject to editing, the contours are well rounded. Display slowdown DTM was not observed on the monitor screen.

\section{AutoCAD Civil 3D}

The main advantage of AutoCAD Civil 3D is that it uses dynamic models. All objects (points, terrain models, roads, etc.) are linked. When the changes to the survey results are made, all related objects are automatically updated. In this program, it is possible not only to build and visually evaluate, but also to edit a 3D terrain model if the need arises.

\subsection{DTM Plotting}

Step-by-step description of the work process:

1. A set of points in a text file format was imported into the drawing. For this, the text file contained four main columns: point identifier, $x, y$ coordinates, elevation $\mathrm{z}$, point code. After importing the points, we got a group of points, displayed in accordance with the style template settings.

2. A surface is created. The surface in Civil 3D was built according to the following algorithm: a new surface is created by clicking the "Surface - Create" tab (set its name), then the "Pointing Device - Surfaces" tab (select our surface). "Definition - Point Group", right-click "Add Point Group". The surface is plotted. In the "Surface Style" tab, the display of the main elements was selected: contour lines, triangles, points, etc. A limit on the length of the triangulation edges is set as $100 \mathrm{~m}$.

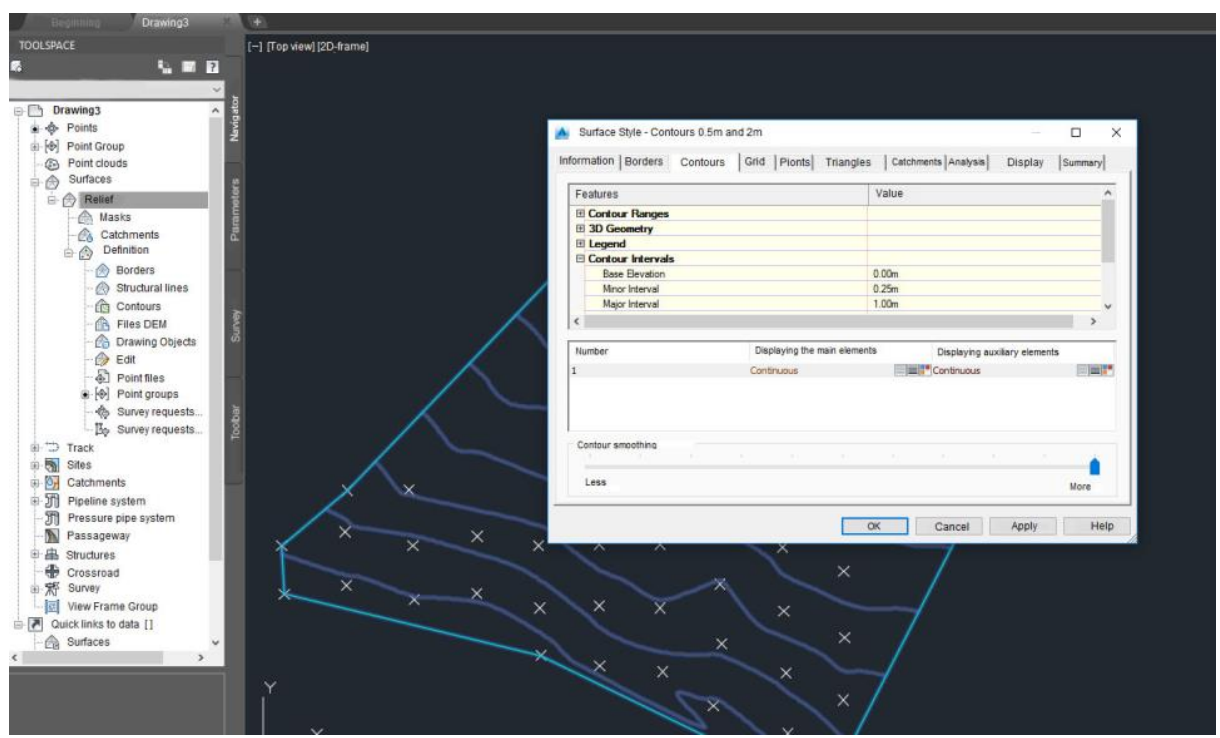

Fig. 3 The basic elements' display tuning

3. The triangles are corrected in the places of relief inflection and unnecessary triangles are removed manually. The constructed digital terrain model is shown in Fig. 3.

Model analysis: in order to achieve greater visibility and realism, more action is needed. The decent contour rounding has not been achieved, although when working with surface styles and points, it was possible to improve the model. 


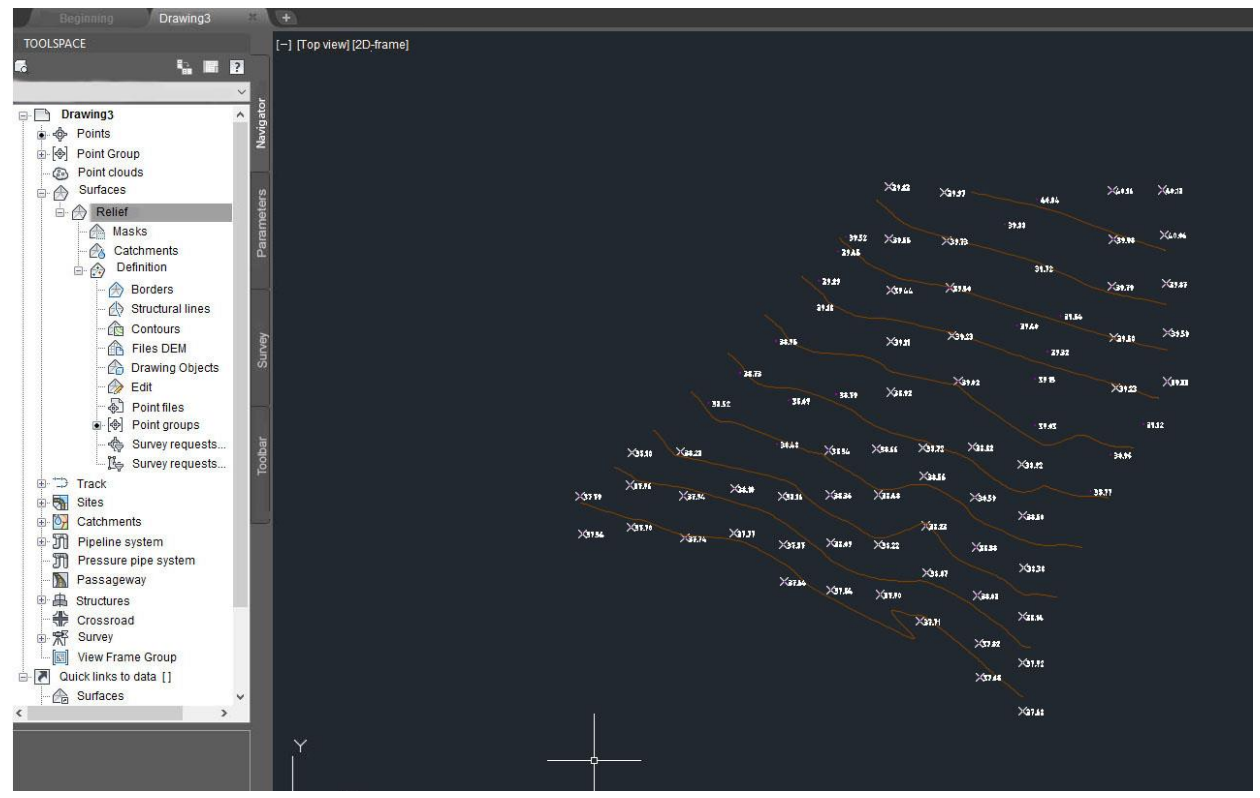

Fig. 4. Digital terrain model

\section{Credo Linear Surveys}

The CREDO software product is used to process the results of engineering surveys, plot a digital terrain model (DTM), design. It is a comprehensive program consisting of several modules. Each module is responsible for a specific design process, but at the same time it is an independent program. The CREDO Linear Survey system, which is a part of the complex, makes it possible to process areal and linear engineering and geodetic surveys and create DTM. The main functionality of this program is to plot DTM irregular grid of triangles [11].

\subsection{DTM Plotting}

1. A new project, for which we save the settings: survey scale, coordinate systems, units, is created. A text file containing names, coordinates and elevations of points, point code, choosing from the drop-down list "Import text file" is imported. The points are loaded into drawing.

2. Before creating DTM the layers are to be organized. Working with layers is similar to the structure of layers in classic AutoCad.

3. Creation of a digital terrain model. Surface - Create Surface - Create on Layer. In the "Parameters" window we set: the maximum edge length $(100 \mathrm{~m})$, the step of the main contours, the interpolation method (linear). 


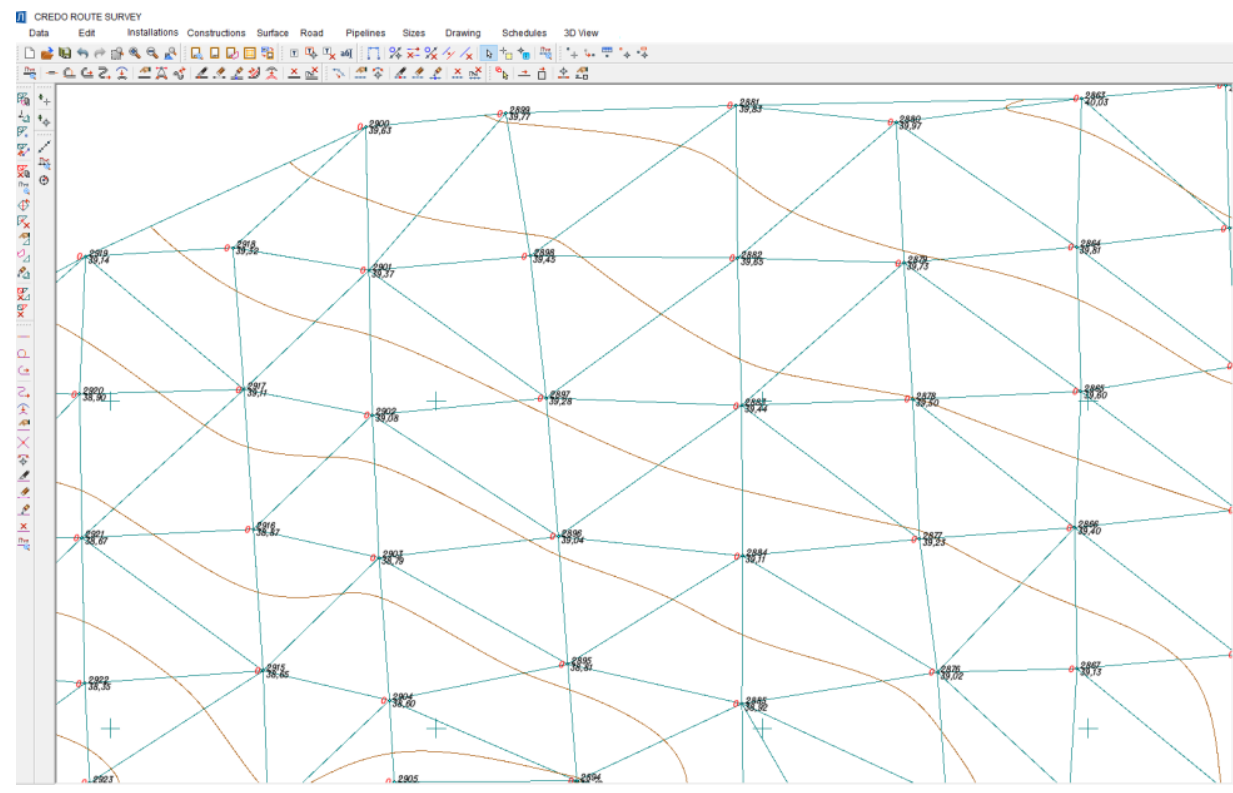

Fig.5. Digital terrain model with triangles

Some edges, along which it is incorrect to perform interpolation, are removed. Some of the triangles are corrected manually by moving the edges. This changes the display of contours, they are smoothed. DTM is created and shown in Fig. 6.

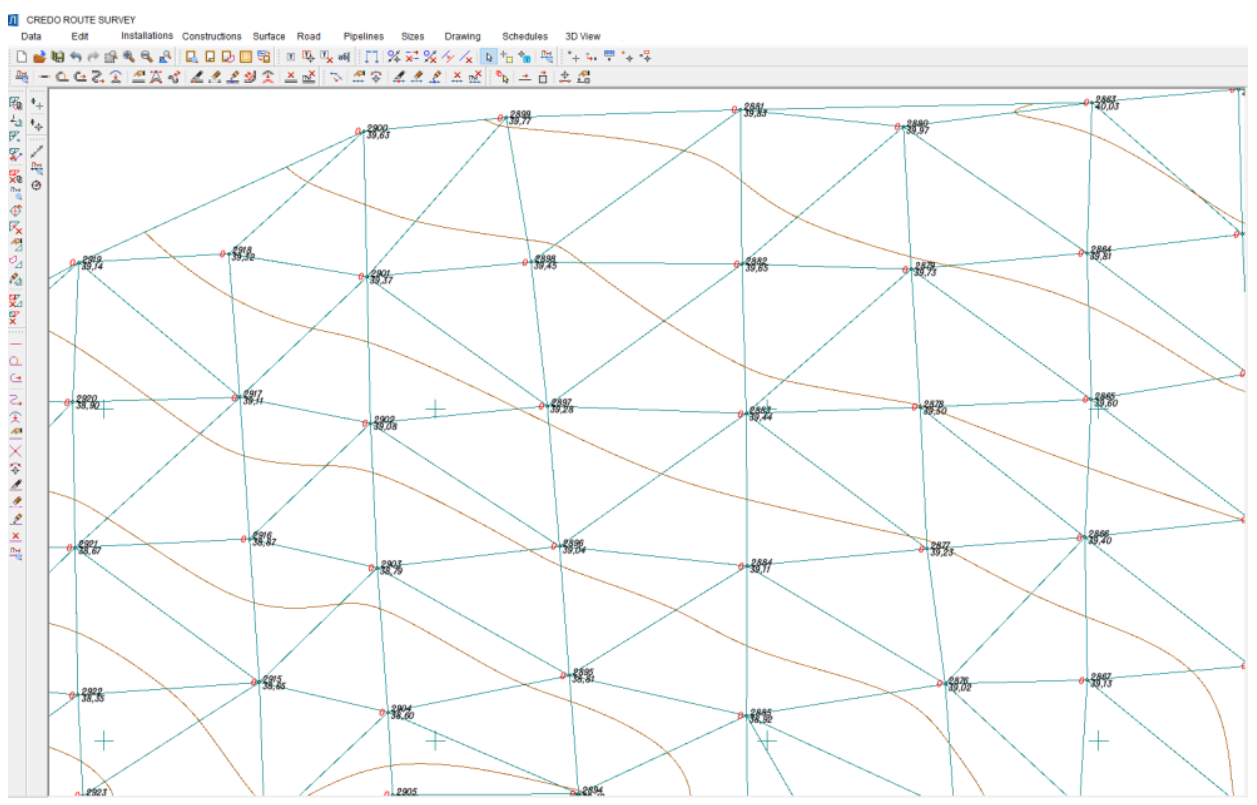

Fig. 6. Digital terrain model

Analysis of the constructed DTM: the display of the model closely matches the real topographic surface, the contours are smoothed well, but the complex interface took more time and action to achieve such results. 


\section{Analysis}

Table 1. Analysis of software products

\begin{tabular}{|c|c|c|c|}
\hline $\begin{array}{c}\text { Evaluation } \\
\text { Criteria } \\
\end{array}$ & Robur - Autoroads & AutoCAD Civil 3D & Credo Linear surveys \\
\hline $\begin{array}{l}\text { Comprehen } \\
\text { sibility of the } \\
\text { interface }\end{array}$ & $\begin{array}{l}\text { In many ways repeats } \\
\text { the classic AutoCad - } \\
\text { many functions in } \\
\text { familiar places }\end{array}$ & $\begin{array}{l}\text { The interface } \\
\text { resembles the classic } \\
\text { AutoCad, but has } \\
\text { additional } \\
\text { functionality }\end{array}$ & $\begin{array}{l}\text { The interface is } \\
\text { complex } \\
\text { overloaded, it is } \\
\text { impossible to navigate } \\
\text { intuitively }\end{array}$ \\
\hline Number of actions & $16-18$ & $20-25$ & $20-22$ \\
\hline $\begin{array}{l}\text { The approximate } \\
\text { time for plotting } \\
\text { the declared } \\
\text { model (taking into } \\
\text { account editing) }\end{array}$ & $5-10 \mathrm{~min}$ & $15 \mathrm{~min}$ & $\mathrm{Up}$ to $20 \mathrm{~min}$ \\
\hline File weight & $3.0 \mathrm{MB}$ & $3.75 \mathrm{MB}$ & $3.9 \mathrm{MB}$ \\
\hline $\begin{array}{l}\text { Plotting accuracy } \\
\text { (in comparison } \\
\text { with a real } \\
\text { topographic } \\
\text { surface) }\end{array}$ & $\begin{array}{l}\text { Sufficiently accurate } \\
\text { construction }\end{array}$ & $\begin{array}{l}\text { Accurate, but more } \\
\text { action needed }\end{array}$ & $\begin{array}{l}\text { Sufficiently accurate } \\
\text { construction, more } \\
\text { action needed }\end{array}$ \\
\hline $\begin{array}{l}\text { One license cost, } \\
\text { rub. }\end{array}$ & 65900 & 113481 & 92500 \\
\hline $\begin{array}{c}\text { DEMO version } \\
\text { available }\end{array}$ & $\begin{array}{c}\text { Yes, for non- } \\
\text { commercial purposes } \\
\text { for free }\end{array}$ & Yes, 30 days & Yes, for 2 weeks \\
\hline $\begin{array}{l}\text { Import-export } \\
\text { (main formats) }\end{array}$ & DXF, Shapefile SHP & $\begin{array}{c}\text { DXF, Shapefile SHP, } \\
\text { Google KML }\end{array}$ & $\begin{array}{l}\text { drawing to DXF files, } \\
\text { points to NXYH text } \\
\text { files; DTM export to } \\
\text { raster formats }\end{array}$ \\
\hline $\begin{array}{c}\text { Working with } \\
\text { encoding }\end{array}$ & yes & yes & yes \\
\hline
\end{tabular}

\section{Conclusion}

Automation of field and office geodetic works significantly speeds up and facilitates the process of work, increases the accuracy of the created models. It should be noted here that the professionalism of the surveyor also plays an important role in this. So, for example, when constructing DTM, the TIN model has to be corrected manually: by deleting or redeploying the grid edges.

If we talk about the programs under study, most specialists cannot give preference to any one, since each of them has its pros and cons [4].

Note that the Robur software package is more often used by the organizations conducting the surveys of linear structures (roads and railways), since it is possible to work in the network and in the same model with the designers; it does not require more than the special characteristics of a computer to work.

AutoCAD Civil 3D requires a powerful computer and a particularly large amount of free memory, it is possible to add a palette with topographic conventional symbols, a 
familiar interface, is more popular among the surveyed researchers, despite the slowdown in data processing speed with increasing file weight and drawing load.

The program Credo Linear surveys, according to the group of researchers, is unusual and overloaded with functions and objects, a powerful computer and a large amount of free memory are required, otherwise it takes a very long time to plot a model (even with a small number of points).

In conclusion, we note that the choice of one or another software product for geodetic production depends on many factors and is often determined by the power of the computer, the program cost and the personal preferences.

\section{References}

1. M.A. Altyntsev, S.A. Arbuzov, R.A. Popov, G.V. Tsoi, M.O. Gromov, UAV aerial survey: Accuracy estimation for automatically generated dense digital surface model and orthothoto plan, Paper presented at the International Archives of the Photogrammetry, Remote Sensing and Spatial Information Sciences - ISPRS Archives, 41, 155-159 (2016). doi:10.5194/isprsarchives-XLI-B6-155-2016

2. A.E.Dudnik, O.V. Germak, G.K. Tupoleva, IOP Conference Series: Materials Science and Engineering 698 (4) (2019). doi:10.1088/1757-899X/698/4/044006

3. A.V. Chepyzhova, E.A. Pravdina, O.Y. Lepikhina, Journal of Physics: Conference Series 1333(3) (2019). doi:10.1088/1742-6596/1333/3/032064

4. O. Germak, O. Gugueva, N. Kalacheva, IOP Conference Series: Materials Science and Engineering 913 (4), (2020). doi:10.1088/1757-899X/913/4/042028

5. O.V. Germak, O.A. Gugueva, N.A. Kalacheva, Engineering Studies 3 (2), 10, 300-876 (2018).

6. D. Gura, I. Markovskii, B. Hahuk, S. Pshidatok, IOP Conference Series: Materials Science and Engineering 698 (4) (2019). doi:10.1088/1757-899X/698/4/044014

7. N. Samsonova, O. Shevtchenko, MATEC Web of Conferences 212, (2018). doi:10.1051/matecconf/201821204019

8. V. Yakovlev, I. Korzhenevskaya, IOP Conference Series: Materials Science and Engineering 698 (4), (2019). doi:10.1088/1757-899X/698/4/044007

9. M. Baborykin, Bulletin of the Tomsk Polytechnic University, Geo Assets Engineering 331(7), 161-175 (2020)ю doi:10.18799/24131830/2020/7/2727

10. Official site - https://credo-dialogue.ru/produkty/korobochnye-produkty/377-credoliniz-naznachenie.html 